\title{
Os jardins históricos: da dimensão patrimonial ao seu potencial turístico
}

\section{The historic gardens: from the heritage dimension to its tourist potential}

\author{
Susana Silva (SILVA, S.) ${ }^{*}$ \\ Paulo Carvalho (CARVALHO, P.) ${ }^{* *}$
}

\begin{abstract}
RESUMO - O património cultural e paisagístico ligado aos jardins históricos configura um recurso turístico estratégico dos territórios e, não raras as vezes, incorpora elementos da identidade e imagem dos mesmos, constituindo por isso, documentos culturais e históricos fundamentais na preservação e fortalecimento da memória cultural e da identidade coletiva de uma sociedade, assim como atrações turísticas por si só e por direito próprio. Tendo como matriz metodológica uma revisão aprofundada da literatura científica e dos principais documentos orientadores e normativos internacionais de referência, contextualizou-se a dimensão patrimonial dos jardins históricos e explicitouse a sua dimensão turística e lúdica atual. Como principais conclusões referem-se a relevância do turismo de jardins em países como, por exemplo, a França e o Reino Unido, bem como o potencial deste nicho para a atividade turística em Portugal.
\end{abstract}

Palavras-chave: Património Histórico/Cultural; Jardins Históricos; Turismo de Jardins.

ABSTRACT - The cultural and landscape heritage linked to the historic gardens set up a strategic tourist resource of the territories and, not rare times, incorporates elements of identity and image of them, constituting therefore, fundamental cultural and historical documents in the preservation and strengthening of a society cultural memory and collective identity, as well as tourist attractions in themselves and in their own right. The methodology was based on a depth review of the scientific literature and the main international guiding and normative documents, in order to contextualize the patrimonial dimension of the historic gardens and clarify its current tourist and recreational dimension. As main conclusions this paper refers the relevance of the garden tourism in countries such as France and the United Kingdom, as well as the potential of this niche to the tourist activity in Portugal.

Key words: Historical/Cultural Heritage; Historic Gardens; Garden Tourism.

\footnotetext{
* Licenciatura em Geografia, área de especialização em Ambiente e Desenvolvimento (Faculdade de Letras. Universidade de Coimbra). Mestrado em Geografia Humana - Ordenamento do Território e Desenvolvimento (Faculdade de Letras. Universidade de Coimbra). Doutoranda do curso de Geografia Humana (Universidade de Coimbra). Investigadora do Centro de Estudos de Geografia e Ordenamento do Território (CEGOT) das Universidades de Coimbra, Porto e Braga. Endereço para correspondência: Faculdade de Letras, Largo da Porta Férrea, 3004-530 - Coimbra (Portugal). Telefone: 351239859900. Email: susanageog@sapo.pt

** Licenciatura, Mestrado e Doutorado em Geografia pela Universidade de Coimbra. Professor Auxiliar do Departamento de Geografia da Faculdade de Letras de Coimbra e Investigador do Centro de Estudos de Geografia e Ordenamento do Território (CEGOT) das Universidades de Coimbra, Porto e Braga. Diretor da Licenciatura em Turismo, Lazer e Património. Docente do Mestrado em Lazer, Património e Desenvolvimento e do Doutoramento em Turismo, Lazer e Cultura da Universidade de Coimbra. Endereço para correspondência: Faculdade de Letras, Largo da Porta Férrea, 3004-530 - Coimbra (Portugal). Telefone: 351239859900. E-mail: paulo.carvalho@fl.uc.pt
} 


\section{INTRODUÇÃO'}

A segunda metade do século XX marca a extensão do conceito de património a outras dimensões para além do monumento edificado motivado, entre outros, pelo crescente interesse pelas paisagens, sítios e monumentos naturais, que se estende aos jardins que, uma vez transversais às diferentes civilizações e sociedades, constituem documentos culturais e históricos de grande importância, fundamentais na preservação e fortalecimento da memória cultural e da identidade coletiva de uma sociedade.

A necessidade e a importância de se conhecer e salvaguardar os jardins proporcionaram um contexto de mudanças e oportunidades, em particular desde final da década de 60 do século passado culminando em 1981 com a publicação da Carta de Florença (ICOMOS, 1982) que fixou, para além de um novo rumo, uma proteção específica para os jardins e que constitui, desde então, o principal documento orientador das ações perpetradas pelos países com relação aos mesmos.

Os jardins históricos constituem atrações por si só pelo seu valor intrínseco e, no seio de um contexto turístico competitivo e exigente, têm sido identificados como recursos estratégicos dos territórios e, não raras as vezes, incorporam elementos da identidade e imagem dos mesmos, nomeadamente das cidades, já que alguns dos mais famosos sítios turísticos são jardins ou estão associados a jardins ou ainda porque são palco ou motivo para eventos e festivais mundiais.

Os jardins e a sua visita constituem um fenómeno do turismo cultural e de recreação da sociedade pós-moderna para diversos autores, facto que dá o mote para uma reflexão mais profunda sobre o percurso do jardim histórico, desde a dimensão patrimonial institucionalizada no quadro de alguns documentos e ações internacionais e nacionais, à importância que têm adquirido como recurso turístico/lúdico, no seio da atividade turística e dos próprios territórios onde se inserem, com potencialidades por conhecer e explorar, analisada igualmente sob uma perspetiva nacional e internacional. Os jardins, enquanto espaços multidimensionais e multifuncionais, são cada vez mais locais de visita e de atividades várias, como tal estão na ordem do dia no contexto internacional e o turismo de jardins experiencia um crescimento notável.

\footnotetext{
${ }^{1}$ Publicado no idioma português de Portugal.
} 


\section{OS JARDINS ENQUANTO PATRIMÓNIO CULTURAL}

Transversais às diferentes civilizações e sociedades, os jardins transformaram-se em documentos culturais, artísticos e históricos de grande importância, “[...] El jardín, reflejo de la cultura y de la historia de um Pueblo, es una de las más hermosas formas de acercarse a este património vivo de nuestro passado y nuestra conciencia humana" (AÑóN, 1993, p. 25), e por isso testemunhos fundamentais na preservação e fortalecimento da memória cultural e da identidade coletiva de uma sociedade (ANDRADE, 2008).

Os jardins e o seu estilo refletem, na maioria das vezes, as características dos seus períodos de formação e desenvolvimento (SIMKOVIC, 1977), assim como poderes pessoais e políticos. Veja-se os exemplos do jardim de Versailles, símbolo do absolutismo de Luís XIV, a obra-prima de Le Nôtre e o expoente máximo do estilo renascentista francês (VITERBO, 1906; CARITA e CARDOSO, 1987) ou de Kew que se tornou num elemento chave do Império Britânico ao afirmar-se como centro de economia e exploração botânica (JOHNSON, 2007).

O interesse pelos jardins nasce por altura das Exposições Universais e Internacionais, ocorridas antes da $2^{\mathrm{a}}$ Guerra Mundial, tendo sido as anfitriãs dos primeiros encontros a respeito. Por ocasião da Exposição de Bruxelas (1935) surge um primeiro grupo de arquitetos paisagistas que se debruça sobre o tema que, mais tarde se consolida na Exposição de Paris (1937), e a criação da IFLA $^{2}$ (1948) constitui uma das primeiras concretizações deste interesse (PECHÈRE, 1987; LUMMEN, 2001).

Apesar de longamente secundarizado é no contexto da necessidade de se conhecer e salvaguardar este património que os jardins experimentam mudanças e oportunidades, em particular desde final da década de 60 do século XX, quando a IFLA (reunida na Sardenha - Itália, durante a sua Assembleia Geral) criou uma Secção específica, na altura pioneira, sob coordenação de René Pechère, para discutir uma metodologia para tratar os jardins com interesse histórico (PECHÈRE, 1987; LUMMEN, 2001; ANDRADE, 2008). Os principais objetivos desta Secção passavam por inventariar e elaborar uma lista dos jardins históricos existentes no mundo, pesquisar os meios de proteção, conservação, restauração e manutenção mais

${ }^{2}$ Federação Internacional de Arquitetos Paisagistas (IFLA - International Federation of Landscape Architecture) fundada em 1948 na Universidade de Cambridge (Inglaterra). 
adequados, analisar e registar as regras de composição da arquitetura e dos elementos vegetais que deveriam ser respeitados, e intervir por forma a impedir a destruição desses espaços (PECHÈRE, 1971).

A fundação do Comité Internacional de Jardins e Sítios Históricos, no início da década de 70, como uma sub-divisão do $\operatorname{ICOMOS}^{3}$ e da IFLA, marca o início de uma nova fase na forma de encarar os jardins históricos, tendo como principais objetivos, a nível internacional, nacional e regional, promover a defesa, a reabilitação, o conhecimento e a difusão deste património cultural ameaçado, através do estabelecimento de uma teoria e prática da restauração, alentar uma legislação adequada e formar especialistas preparados para levar adiante a árdua tarefa que representa a recuperação de um jardim histórico (AÑóN, 1993).

O primeiro Simpósio Internacional de Proteção e Restauração de Jardins Históricos (1971), realizado em Fontainebleau sob alçada deste Comité, marca o início de uma discussão que se prolongaria, de forma continuada, até final da década de 80 , e que culminou em 1981 com a publicação da Carta de Florença (ICOMOS, 1982).

Neste documento, o jardim histórico é celebrado como um "Monumento Vivo", testemunho de uma cultura, de um estilo, de uma época e da originalidade de um artista criador, para além de um espaço de sociabilização, meditação e repouso (artigo $5^{\circ}$ ). E, tendo em conta estas particularidades, a Carta de Florença (ICOMOS, 1982) fixou um conjunto de normas orientadoras específicas no que concerne à manutenção, conservação $\left(\operatorname{artigos} 10^{\circ}\right.$ a $17^{\circ}$ ), restauro e reconstrução, uso $\left(\operatorname{artigos} 18^{\circ}\right.$ a $22^{\circ}$ ) assim como à proteção legal e administrativa (artigos $23^{\circ}$ a $25^{\circ}$ ) dos jardins históricos, e constitui, desde então, o principal documento orientador das ações praticadas por todos os países do mundo com relação aos jardins históricos. Veja-se os casos recentes da restauração dos jardins modernos de Burle Marx, a Praça Euclides da Cunha e a Praça Faria Neves (SÁ CARNEIRO, SILVA e MAFRA, 2007) ou até mesmo os trabalhos de restauração e recuperação realizados nos doze jardins portugueses abrangidos pelo projeto Europeu EEA Grants ${ }^{4}$ (SOARES, CHAMBEL e ANDRADE, 2010).

\footnotetext{
${ }^{3}$ International Council on Monuments and Sites (ICOMOS).

${ }^{4}$ O EEA Grants (European Economic Area Financial Mechanism - Mecanismo Financeiro do Espaço Económico Europeu) foi criado em 2004 e é financiado pela Islândia, Liechtenstein e Noruega. Apoia projetos de desenvolvimento económico e social nos domínios da proteção do ambiente, mudanças
} 


\subsection{O CONTEXTO INTERNACIONAL}

Em vários países há muito que foi reconhecido o valor dos jardins históricos como um património maior. De tal forma que têm vindo a ser desenvolvidas estratégias de modo, não só a salvaguardar e a preservar, como a valorizar, potencializar e a otimizar este recurso através da atividade turística, como é o caso de Ontario (Canadá) (OGTC, 2011). Outros casos existem que revelam o sucesso do desenvolvimento e da aplicação de políticas e programas de salvaguarda, revitalização e redinamização dos jardins, como o são o Reino Unido ou a França.

No Reino Unido, considerada a "nation of garden lovers", poder-se-á falar do trabalho há muito desenvolvido por instituições/organizações como a National Trust, a National Garden Scheme ou a Royal Horticultural Society que têm como objetivos manter, preservar, valorizar e promover jardins históricos (MINTER, 2004), mas também em alguns projetos como o Eden Project (Cornwall) e o Alnwick Garden (Northumberland), novas atrações que aumentaram os visitantes das regiões onde estão inseridos e contribuíram para o desenvolvimento económico e turístico dessas áreas rurais (MINTER, 2004; SHARPLEY, 2007).

O primeiro atraiu, em 2001, 500.000 visitantes adicionais para a Cornualha, gerando $£ 111$ milhões de libras em proveitos diretos ( $£ 188$ milhões indiretos e induzidos), originou 435 empregos no local para além de suportar cerca de 3500 empregos na região (SHARPLEY, 2007), figurando no 13 lugar do Top das 20 atrações turísticas pagas mais visitadas em 2011, com 1.001.774 visitantes (VISIT ENGLAND, 2012). Quanto a Alnwick Garden, este ultrapassou as previsões de 67.000 visitantes anuais para 570.000 visitantes em 2003 (abriu em 2001), teve um impacto positivo imediato no aumento de chegadas de turistas à região, no aumento dos investimentos em hotelaria e na qualidade dos serviços prestados assim como no aumento dos negócios locais (SHARPLEY, 2007).

Em França, a proteção e salvaguarda dos parques e jardins está assegurada por um conjunto de normas, das quais se destaca a Lei dos Monumentos Históricos de 1913 (RÉPUBLIQUE FRANÇAISE, 1914) e a Lei sobre os Sítios de 1930 (RÉPUBLIQUE FRANÇAISE, 1930) comportando, cada uma delas, dois níveis de proteção: a

climáticas e energias renováveis, sociedade civil, saúde e crianças, património cultural e atribui bolsas escolares (Informação disponibilizada no endereço eletrónico do EEA Grants, 2012).

Turismo \& Sociedade (ISSN: 1983-5442). Curitiba, v. 6, n. 3, p. 605-625, julho de 2013. 
classificação e a inscrição (inventariação). Assim sendo, os parques e jardins, que sejam de interesse histórico ou artístico, podem beneficiar da proteção/classificação de monumento histórico, e reclamar proteção enquanto Sítios, uma vez constituírem parte integrante e importante de uma paisagem notável.

As instituições também tomam parte ativa em matéria de proteção e ações de salvaguarda dos parques e jardins históricos franceses, nomeadamente com o Comité de Parques e Jardins de França (CPJF) fundado em 1990, o Conselho Nacional de Parques e Jardins (CNPJ) e a Fundação de Parques e Jardins, criados em 2003 e 2008 respetivamente, cujos objetivos passam fundamentalmente pelo conhecimento, proteção, manutenção, restauração, promoção, criação e valorização de parques e jardins de França (MCC, 2003).

A "Politique en faveur des parcs et jardins", institucionalizada em 2003 (MCC, 2012) visa, em traços gerais, a proteção, restauração, manutenção e valorização dos jardins históricos, o desenvolvimento e implementação de planos de gestão e a formação de profissionais, e na qual se inserem ações como o evento anual Rendez-vous aux jardins ou a distinção de Jardin Remarquable.

\subsection{OS JARDINS HISTÓRICOS NO CONTEXTO DO PATRIMÓNIO CULTURAL PORTUGUÊS}

No contexto português, os jardins históricos nunca constituíram uma preocupação ou foram objeto de atenção especial por parte das entidades competentes. Decorrente desta apatia geral muitos exemplares foram desaparecendo por via das novas necessidades urbanas, ou perdendo o seu caráter original e histórico por conta de alterações e remodelações sem regra de que foram alvo, embora existam mecanismos institucionais de proteção e salvaguarda ao nível da legislação, inventariação e classificação, assim como instituições de cariz mais privado que têm trabalhado nesse sentido como a Associação Portuguesa dos Jardins e Sítios Históricos (APJSH).

\subsubsection{Legislação, Inventariação e Classificação}

As primeiras preocupações com os jardins surgem sobretudo no meio académico e por lá se circunscreveram durante muito tempo. Só mais recentemente, na década de 
90 do século XX, se começam a perceber alguns sinais de mudança relativamente aos mesmos, não obstante datarem das primeiras décadas deste século algumas medidas protecionistas relativas a árvores notáveis concretizadas com a criação da "Associação Protetora da Árvore" em 1914 através da Lei 118 de 16-03-1914 (PORTUGAL, 1914) e mais tarde, em 1938 com a publicação do Decreto-Lei n. ${ }^{\circ} 28468$ de 15-02-1938 (PORTUGAL, 1938) que cria a figura das "árvores de interesse público”, recentemente revogada pela Lei n. ${ }^{\circ}$ 53/2012 de 5 de Setembro (PORTUGAL, 2012a) que aprova o regime jurídico de classificação de arvoredo de interesse público, que se identifica agora de forma mais pormenorizada aplicando-se a:

[...] povoamentos florestais, bosques ou bosquetes, arboretos, alamedas e jardins de interesse botânico, histórico, paisagístico ou artístico, bem como aos exemplares isolados de espécies vegetais que, pela sua representatividade, raridade, porte, idade, historial, significado cultural ou enquadramento paisagístico, possam ser considerados de relevante interesse público e se recomende a sua cuidadosa conservação (PORTUGAL, 2012a, p. 5124).

Anterior a esta, era na atual Lei do Património Cultural Português (Lei n. ${ }^{\circ}$ 107/2001 de 8 de setembro) que se encontrava uma referência mais específica aos jardins históricos (artigo $44^{\circ}$ e $70^{\circ}$ ), reconhecendo a sua importância enquanto elementos potenciadores da coerência dos monumentos, conjuntos e sítios que o integram (PORTUGAL, 2001).

Todavia, a preocupação pelos jardins, pelo seu conhecimento, valor cultural e patrimonial que estes representam despontou no início do século $\mathrm{XX}$, com o historiador Viterbo (1906) seguindo-se-lhe, ainda no domínio do inventário, Araújo (1962) e Carapinha (1985). Apesar de tudo, continuava a faltar uma base de dados mais pormenorizada e que abrangesse todo o território português incluindo as ilhas.

Na década de 90, no âmbito do Inventário do Património Arquitetónico (IPA) ${ }^{5}$, foi criada uma base de dados informatizada dos Jardins e Sítios Históricos de Portugal, pela extinta Direção Geral dos Edifícios e Monumentos Nacionais (DGEMN) em

\footnotetext{
${ }^{5}$ O IPA - Inventário do Património Arquitetónico começou a ser elaborado no início da década de 90 do século passado pela extinta Direção-Geral dos Edifícios e Monumentos Nacionais (DGEMN), tendo passado a ser desenvolvido, desde 2007, pelo Instituto da Habitação e Reabilitação Urbana (IHRU, I. P.). O IPA é uma base de dados técnico-científica que documenta o património arquitetónico, urbanístico e paisagístico português e de raiz portuguesa, que está em constante atualização contando, no momento, com cerca de 30.000 registos monográficos (Informação disponibilizada no endereço eletrónico do SIPA e IHRU, 2012).
} 
colaboração com arquitetos paisagistas, docentes da Universidade de Évora. Nela foram registados, descritos e enquadrados historicamente e em termos de classificação legal cerca de 300 Jardins e Cercas, Tapadas e Parques. No final da década de 90 faz-se novo levantamento dos jardins históricos, mas desta feita sob a ótica do seu potencial turístico em Portugal Continental, proposto pelo Instituto de Financiamento e Apoio ao Turismo (então Fundo de Turismo) e realizado por uma equipa de arquitetos paisagistas, chegando-se a um conjunto de cerca de 120 jardins (CASTEL-BRANCO, 2002).

O trabalho de inventariação dos jardins, com ou sem interesse histórico (inseridos agora na grande categoria "Espaço Verde"), continua a ser feito, contando atualmente com pouco mais de 500 referências de jardins, cercas, tapadas, parques e quintas inventariadas (SIPA e IHRU, 2012).

A classificação, a par da inventariação, constitui um processo decisivo na proteção e preservação do património cultural. A partir da base de dados disponibilizada pelo IGESPAR $^{6}$, sistematizou-se a informação relativa à classificação dos jardins portugueses que faziam parte sobretudo de conjuntos, distribuídos pelas tipologias Arquitetura Civil (94 referências), Arquitetura Religiosa (9 referências) e ainda um caso que está inserido na tipologia Não Definida, num total de 104 (quadro 1).

É no âmbito da tipologia Arquitetura Civil que se encontram mais jardins classificados, incluídos não só na categoria Jardim, mas também nas categorias Casa, Conjunto, Palácio, Parque, Quinta, Solar entre outras, em cujas respetivas listagens aparecem exemplos que incluem os jardins correspondentes, num total de 94 referências, 69 já classificadas e 25 em vias de classificação.

A lista que inclui somente jardins é diminuta, uma vez que apenas três se encontram efetivamente classificados. O Jardim da Manga e o Jardim Botânico de Lisboa como Monumento Nacional e o Jardim Botânico de Coimbra como Imóvel de Interesse Público contudo, quando se alarga às outras categorias ascende às 66 as referências a conjuntos classificados onde se incluem jardins.

\footnotetext{
6 Instituto de Gestão do Património Arquitetónico e Arqueológico (IGESPAR) (Informação disponibilizada no endereço eletrónico do IGESPAR, 2012).
} 
QUADRO 1 - JARDINS CLASSIFICADOS E EM VIAS DE CLASSIFICAÇÃO EM PORTUGAL

\begin{tabular}{|c|c|}
\hline CATEGORIAS & TIPO DE PROTEÇÃO \\
\hline \multicolumn{2}{|c|}{ Tipologia Arquitetura Civil } \\
\hline Área Urbana (1) & 1 (IIP) \\
\hline Biblioteca (1) & $1(\mathrm{VC})$ \\
\hline Casal (1) & $1\left(1^{\circ} \mathrm{IIP} / \mathrm{MN}\right)$ \\
\hline Cerca (1) & 1 (IIP) \\
\hline Casa (21) & 13 (IIP); 3 (IM); 5 (VC) \\
\hline Conjunto (5) & 1 (IIP); 4 (VC) \\
\hline Conjunto Urbano (1) & $1(\mathrm{VC})$ \\
\hline Edificio (7) & 3 (IIP); 1 (IM); 1(MIP); 2 (VC) \\
\hline Escola (1) & $1(\mathrm{VC})$ \\
\hline Jardim (3) & $2(\mathrm{MN}) ; 1$ (IIP) \\
\hline Museu (1) & $1(\mathrm{MN})$ \\
\hline Paço (2) & 2 (IIP) \\
\hline Palacete (4) & $1(\mathrm{MN}) ; 1$ (IIP); 1 (IM); 1 (VC) \\
\hline Palácio (18) & 5 (MN); 1 (MIP); 10 (IIP); 2 (VC) \\
\hline Parque (3) & 1 (IIP); 1 (IM); 1 (VC) \\
\hline Quinta (16) & 9 (IIP); 1 (IM); 1 (SIP); 5 (VC) \\
\hline Solar (7) & 4 (IIP); 1 (IM); 2 (VC) \\
\hline Tapada (1) & 1 (IIP) \\
\hline TOTAL: 94 & 10 MN; 2 MIIP; 48 IIP; 8 IM; 1 SIP; 25 VC \\
\hline \multicolumn{2}{|c|}{ Tipologia Arquitetura Religiosa } \\
\hline Capela (1) & 1 (IIP) \\
\hline Convento (4) & $2(\mathrm{MN}) ; 2$ (IIP) \\
\hline Igreja (1) & $1(\mathrm{MN})$ \\
\hline Paço (2) & 2 (IIP) \\
\hline Santuário (1) & 1 (IIP) \\
\hline TOTAL: 9 & $3 \mathrm{MN} ; 6$ IIP \\
\hline \multicolumn{2}{|c|}{ Tipologia Não Definida } \\
\hline Conjunto (1) & $1(\mathrm{VC})$ \\
\hline TOTAL: 1 & $1-\mathrm{VC}$ \\
\hline
\end{tabular}

Fonte: IGESPAR (Atualizado a 31 de outubro de 2012).

Legenda: MN - Monumento Nacional, MIP - Monumento de Interesse Púbico, IIP - Imóvel de Interesse Público, IM - Interesse Municipal, SIP - Sítio de Interesse Público, VC - Em Vias de Classificação.

\subsubsection{A Associação Portuguesa dos Jardins e Sítios Históricos}

Os jardins históricos encontram-se dispersos por todo o território português, o que dificulta o seu conhecimento e por isso os torna mais vulneráveis à degradação ou até mesmo ao total e irremediável desaparecimento. Um dos fatores que levou à criação da APJSH, em 2003, foi agrupar os proprietários dos jardins (neste momento conta com cerca de 70) em torno de um interesse comum - a preservação dos jardins históricos, 
cuja dispersão dos mesmos comprometia e inviabilizava a sua necessária manutenção, preservação e valorização (APJSH, 2012).

A APJSH tem por objetivo principal promover a conservação e valorização de sítios naturais e históricos, de caráter privado e público, entendidos como espaços de valor estético, interesse científico, cultural, educativo, turístico e paisagístico. E, foi neste sentido, que apresentou duas candidaturas ao projeto europeu EEA Grants. Uma em 2006 centrada na Recuperação de sistemas hidráulicos, muros e caminhos em jardins históricos e, mais tarde, em 2008, a candidatura que visava o Desenvolvimento dos jardins históricos como produtos turísticos (APJSH, 2012).

O primeiro projeto (para o qual se conhecem dados) teve como principal propósito restaurar os sistemas hidráulicos originais, aproveitar racionalmente os recursos naturais e introduzir sistemas de gestão equilibrada da água por forma a atingir a sustentabilidade ecológica. Foi iniciado em setembro de 2007, teve uma duração de 36 meses e um investimento total de 1.084.324€, sendo que 60\% (650.594€) proveio do investimento EEA Grant, que foi dividido/distribuído por 12 jardins associados (quadro 2) (SOARES, CHAMBEL e ANDRADE, 2010).

QUADRO 2 - DISTRIBUIÇÃO DO INVESTIMENTO POR JARDINS

\begin{tabular}{llrr}
\multicolumn{1}{c}{ Jardim } & \multicolumn{1}{c}{ Localização } & Investimento $€$ & \multicolumn{1}{c}{$\%$} \\
\hline Palácio da Fronteira & Lisboa & $197.193,95$ & 21,1 \\
Convento do Bom Sucesso & Lisboa & $23.416,00$ & 2,5 \\
Jardim José do Canto & Ponta Delgada & $72.152,52$ & 7,7 \\
Quinta da Boa Viagem & Viana do Castelo & $107.772,29$ & 11,5 \\
Jardim do Paço Vitorino & Ponte de Lima & $83.149,24$ & 8,9 \\
Jardim da Casa de Juste & Lousada & $74.795,00$ & 8,0 \\
Jardim Botânico de Coimbra & Coimbra & $52.843,01$ & 5,6 \\
Quinta das Lágrimas & Coimbra & $158.198,34$ & 16,9 \\
Quinta das Machadas & Setúbal & $84.748,50$ & 9,1 \\
Quinta do Senhor da Serra & Sintra & 26.745 .00 & 2,9 \\
Quinta de Santo António & Lisboa & $35.561,93$ & 3,8 \\
Quinta da Francelha & Loures & $19.436,22$ & 2,1 \\
Total & & $\mathbf{9 3 6 0 1 2 , 0 0}$ & $\mathbf{1 0 0}$ \\
\hline Fonte: Elaboraçã propra
\end{tabular}

Fonte: Elaboração própria com base nos dados apresentados por SOARES, CHAMBEL e ANDRADE (2010).

Só a intervenção nos jardins do Palácio da Fronteira correspondeu a 21,1\% do investimento total gasto nos trabalhos de recuperação e restauração, seguido da Quinta das Lágrimas onde foi gasto quase $17 \%$ desse investimento. Pelo contrário, os jardins da Quinta da Francelha e o Claustro do Convento do Bom Sucesso foram os projetos com 
menor dinheiro gasto (2,1\% e 2,55 respetivamente) (quadro 2) (SOARES, CHAMBEL e ANDRADE, 2010).

\section{OS JARDINS (HISTÓRICOS) ENQUANTO ESPAÇOS/ATRAÇÕES TURÍSTICAS}

Nas últimas duas décadas a atividade turística também sofreu alterações, tanto no sentido da oferta como da procura. As massas deixaram de satisfazer o turista, o que tem proporcionado espaço ao aparecimento e desenvolvimento de segmentos turísticos alimentados por um turista mais seletivo, mais exigente e mais complexo (SIMÕES e FERREIRA, 2009), que configura uma procura mais fragmentada e menos uniformizada e padronizada (NOVELLI, 2005) e mais assente em experiências únicas (NETTO e GAETA, 2011).

Nesta linha reflexiva inserem-se os jardins e parques históricos que constituem cenários privilegiados em termos visuais, levando mesmo Wanhill $\left(2003^{7}\right.$, citado em FOX, 2006) a classificá-los como a única forma de imagescape, para além de importantes componentes da green-scape e parte insubstituível da paisagem histórica (WILSON, 2009). Para Evans (2001), os jardins constituem atrações turísticas por si só e por direito próprio e por isso são cada vez mais identificados como um importante recurso no seio do produto turístico regional e até mesmo nacional já que, não raras as vezes incorporam elementos de identidade e imagem dos territórios (Central Park, Versailles, Keukenhof, Kew Gardens ou os Classical Gardens of Suzhou), e a sua visita considerada uma forma de turismo cultural na sociedade pós-moderna que adquire um papel relevante no tempo e necessidades de lazer do turista contemporâneo (CONNELL, 2004; ASSUNÇÃO, 2008).

Ao caráter atrativo intrínseco dos jardins acrescenta-se o aumento do interesse pelos temas relacionados com jardins, jardinagem e paisagem que motivam, muitas vezes, a realização de eventos relacionados e que são responsáveis tanto pela atração de inúmeros visitantes como da promoção e imagem dos territórios que os acolhem

\footnotetext{
${ }^{7}$ WANHILL, S. Interpreting the development of the visitor attraction product. In: FYALL, A.; GARROD, B.; LEASK, A. (Eds.) Managing visitor attractions: new directions. Oxford: ButterworthHeinemann, 2003. p. 16-35.
} 
(ARAMA-CARREL, 2006). São exemplo os Federal Garden Shows na Alemanha, o Chelsea Flower Show no Reino Unido, a Floríade na Holanda ou ainda em França o Festival de Chaumont-sur-Loire e o evento Rendez-vous aux jardins (figura 1).

Em Portugal, o evento de caráter internacional de maior destaque é a Festa da Flor da Madeira (figura 2) que se realiza anualmente nesta ilha e que é responsável por uma das mais elevadas taxas de ocupação hoteleira, assim como pelo aumento do tráfego de passageiros, tanto no aeroporto como nos portos (DRTM,2011a; 2011b).
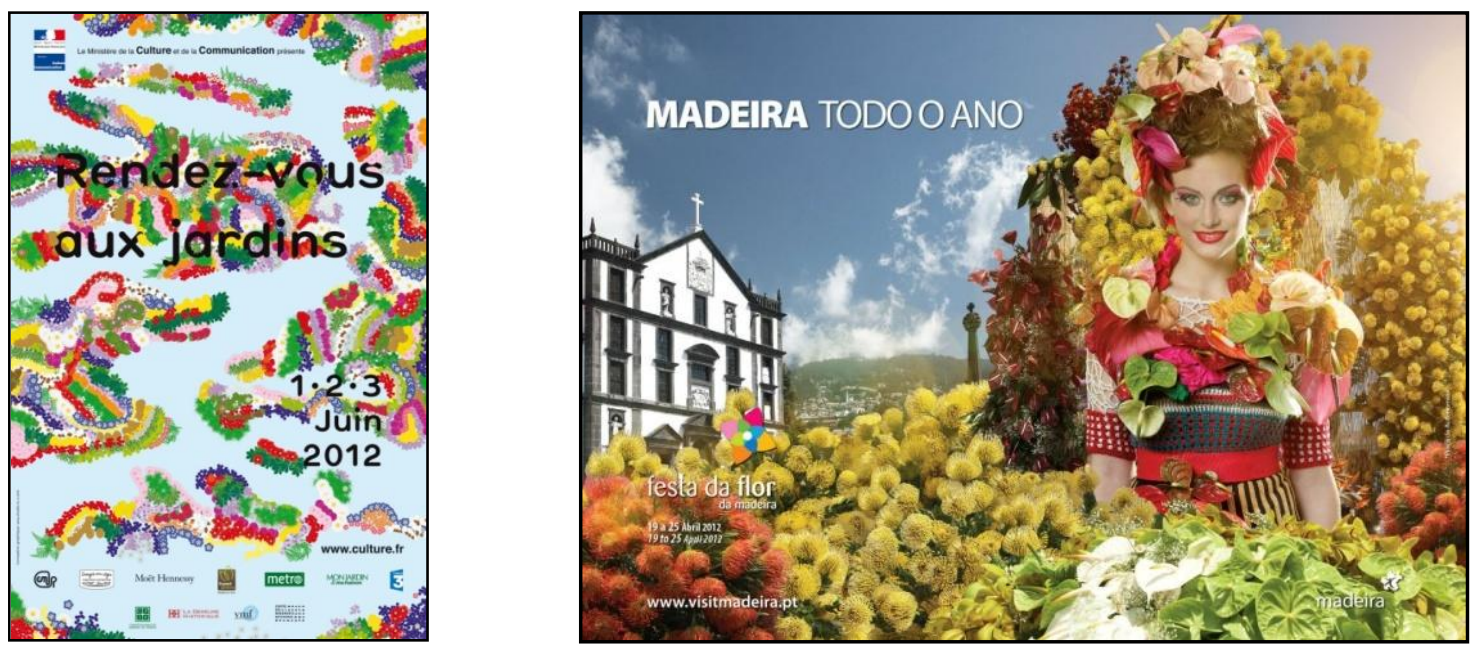

FIGURAS 1 e 2 - CARTAZ PUBLICITÁRIO DO RENDEZ-VOUS AUX JARDINS EM FRANÇA E DA FESTA DA FLOR NA MADEIRA, 2012.

Fontes: MCC (2012) e VISITMADEIRA (2012).

\subsection{O CONTEXTO INTERNACIONAL DO TURISMO DE JARDINS/GARDEN} VISITING

O turismo de jardins tem origens na Europa, nomeadamente em Inglaterra através dos garden tours e na Alemanha com os conhecidos Federal Garden Shows (THOMAS, PORTEOUS e SIMMONS, 1994), mas não lhe é exclusiva. Países como a Nova Zelândia, Austrália, Singapura, Japão, Irlanda, Holanda, Canadá ou Estados Unidos da América (THOMAS PORTEOUS e SIMMONS, 1994; EVANS, 2001; FOX, 2006; FOX, 2007; BLANDIGNERES e RACINE, 2002; CONNELL e MEYER, 2004), estão também há muito familiarizados com este tipo particular de turismo. Constitui, no entanto, uma novidade as proporções e a dimensão que vem tomando no seio da atividade turística global (BHATTI e CHURCH, 2000; CONNELL, 2004; CONNELL, 
2005), facto que o leva a ser considerado como um fenómeno (CONNEL e MEYER, 2004; MÜLLER, 2011; BENFIELD, 2013).

A visita a jardins mobiliza nos EUA mais de 40 milhões de turistas/visitantes (BENFIELD, 2013). Na Grã-Bretanha, no início do século XXI, os visitantes excediam 16 milhões (EVANS, 2001). Em Inglaterra, em 2011, figuravam três jardins no TOP 20 das atrações pagas (Kew Gardens, RHS Garden Wisley e Eden Project) que atraíram mais de 3 milhões de visitantes (14\% do total de visitantes destas 20 atrações) (VISIT ENGLAND, 2012). Na Austrália os 123 Jardins Botânicos, Arboretos e Herbários a operar em 1999/2000 foram visitados por 11,8 milhões de pessoas (AUSTRALIAN BUREAU OF STATISTICS, 2001). Já na Áustria, os 24 membros do Gardens of Lower Austria têm recebido nos últimos anos cerca de 1,5 milhões de visitantes, cujos proveitos calcula-se que cheguem aos 75 milhões de euros (DIE GARTEN, 2007). Em França tem-se registado uma multiplicação de aberturas de parques e jardins ao público (passou-se de 150 em 1991 para 750 em 2000 e mais de 1400 em 2007) e uma explosão de eventos ao longo do ano com destaque para o evento Rendez-vous aux jardins, onde em 2011 cerca de 2200 jardins atraíram 1,8 milhões de visitantes (MCC, 2012). Os dados disponíveis revelam que em 2000 um conjunto de 405 jardins atraíram 25 milhões de turistas (DELADERRIÈRE, 2004).

\subsection{O CENÁRIO ATUAL DO TURISMO DE JARDINS/GARDEN VISITING EM PORTUGAL}

Em Portugal este segmento de turismo é praticamente desconhecido e oficialmente não existe enquanto produto organizado por si só, devido essencialmente à falta de interesse pelos jardins ao nível científico, académico e profissional, ao desconhecimento da real oferta e condições da mesma, aos quais se acrescenta a falta de promoção, organização e comercialização do produto. Todavia, tendo por base o conjunto de produtos delineados como estratégicos no Plano Estratégico Nacional do Turismo (PENT) (PORTUGAL, 2012b) e pelas suas características, o turismo de jardins poder-se-á incluir no grande produto Touring Cultural e Paisagístico.

Uma pesquisa feita na internet, inserindo as expressões em língua inglesa "garden tours in Portugal" e "garden tourism in Portugal" e francesa "tours des jardins 
aux Portugal" e "tourisme des jardins aux Portugal", no motor de busca Google, revelou que existe um importante conjunto de operadores provenientes de Inglaterra, França, Austrália, Nova-Zelândia, Canadá, EUA e também Portugal que vendem o produto turismo de jardins no país, em forma de férias especializadas ou como oferta secundária, com cerca de 20 operadores, de entre os quais 6 portugueses, totalizando uma oferta de quase 30 pacotes de garden tourism em Portugal (figuras 3 e 4).
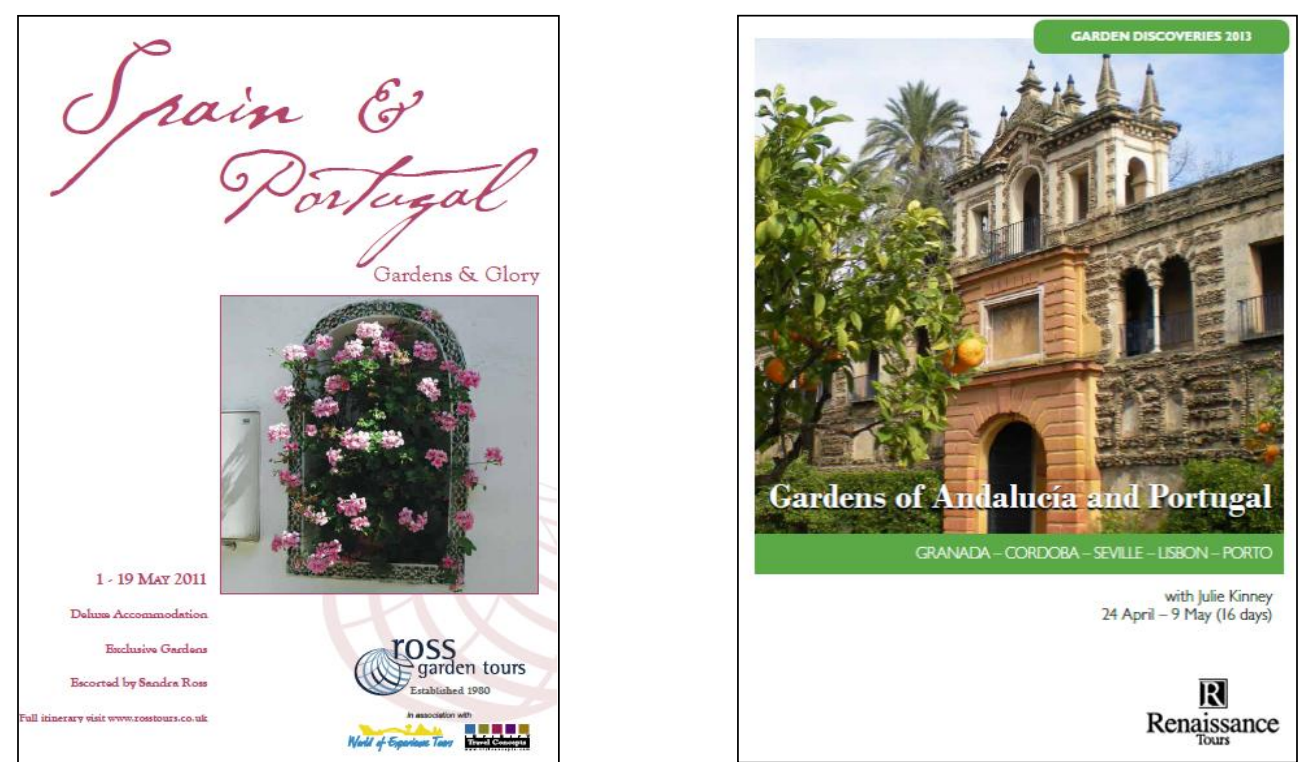

FIGURAS 3 e 4 - EXEMPLOS DE PROGRAMAS DE GARDEN TOURS (ROSS TOURS - REINO UNIDO E RENAISSANCE TOURS - AUSTRÁLIA).

Fonte: Endereços eletrónicos da Ross Tours e Renaissance Tours (2012).

Em Portugal não existem jardins grandiosos como os britânicos, franceses ou italianos mas, o hábito das quintas de recreio das classes abastadas traduziu-se numa herança rica em exemplos deste tipo de jardim mais restrito. Tendo em conta esta realidade, questiona-se: O que faz com que os jardins portugueses sejam (ou possam ser) tão diferentes e ao mesmo tempo tão atrativos? A localização entre o Mediterrâneo e o Atlântico, o clima, a história sociopolítica e económica e a topografia acidentada deixaram impregnados nos jardins (históricos) portugueses um conjunto de traços característicos que, de forma isolada ou combinada, lhes conferem um caráter e originalidade diferentes dos grandes jardins europeus a que o seu comum público estará habituado: a diversidade de árvores e arbustos, as vistas profundas e de diversos níveis, os azulejos e os grandes planos de água, aos quais se juntam os embrechados e os altos 
muros, elemento que consolidava o conceito de jardim como espaço cripto-mágico, que se encontram, de forma conjugada principalmente nas grandes quintas de recreio do século XVI ao XVIII (VITERBO, 1906; ARAÚJO, 1962; CARITA e CARDOSO, 1987).

É na Madeira que a procura deste segmento turístico é mais intensa, porque se trata de um pólo turístico geral há muito consolidado, porque tem um público maioritariamente estrangeiro composto por turistas provenientes do Norte e Centro da Europa (nomeadamente ingleses e alemães) e ainda porque reúne um conjunto de jardins dos mais ricos exemplares nacionais. Só os 3 principais jardins da ilha (Jardim Botânico da Madeira, Jardim Tropical Monte Palace e Quinta do Palheiro Ferreiro) atraem mais de 650 mil visitantes anuais originando uma receita superior a 3,5 milhões de euros (QUINTAL, 2009).

No Continente, o número de jardins, parques, tapadas, cercas e quintas presentes é considerável, estando inventariados cerca de 500 e, embora não se conheçam os dados relativos à frequência da grande maioria, podem referir-se como exemplos o Parque de Serralves (Porto) onde a vertente turística está bem presente e desenvolvida, com visitantes anuais na ordem dos 100 mil (FUNDAÇÃO SERRALVES, 2011), números em muito influenciados pela atração âncora, o Museu de Arte Contemporânea, e o Jardim Botânico de Coimbra, onde é a vertente educativa a que sobressai, alcançando cerca de 10 mil visitantes escolares (visitas guiadas) em 2011 (TAVARES, 2012). A estes números relacionados com visitas marcadas e pagas, acresce um número considerável de visitantes que todos os dias estão no jardim que não pagam bilhete e por isso não são registados, dificultando a sua contabilização. Para além destes, destaque ainda para o jardim do Palácio Marquês de Fronteira (Lisboa) que ultrapassou os $11 \mathrm{mil}$ visitantes pagos em 2012 (FUNDAÇÃO CASAS DE FRONTEIRA E ALORNA, 2012).

\section{CONCLUSÕES}

Os jardins fazem parte da vida humana desde tempos remotos, estando a história dos jardins e a história da humanidade indissociavelmente ligadas. De tal forma que 
estão amplamente retratados, desde o contexto historicista ao funcionalista, ou ainda ao simbólico e misticista. Por isso, não restarão dúvidas quanto à sua importância nas sociedades e nos territórios e, por conseguinte, enquanto elementos privilegiados do património cultural.

O percurso para o seu reconhecimento foi pautado por várias resistências e até mesmo por dificuldades concretas, no entanto, valeu a determinação e a argumentação sólida de um conjunto de personalidades e instituições que traçaram um novo rumo e atitude perante este tipo particular de património, tão rico mas tão vulnerável. Atitude, esta, corporizada na Carta de Florença (ICOMOS, 1982), que constitui ainda, aos dias de hoje, o principal documento orientador com relação aos jardins históricos. Contudo, no que a este património diz respeito, nem tudo está conquistado e alcançado, tratandose por isso de uma luta diária, constante e persistente. E assim terá que ser quando se é confrontado com a degradação de memórias, não raras as vezes com a sua substituição e muitas vezes com a sua completa destruição.

Uma das formas de preservar e perpetuar essas memórias é através da atividade turística adaptada ao tipo de realidade em causa de forma sustentada e sustentável, rebuscando, aliás, uma das funções ancestrais dos jardins, a de lazer e recreio, e que constitui talvez um dos principais motivos e motivações para a recuperação, salvaguarda e valorização deste património.

O turismo de jardins é considerado um fenómeno a nível internacional e apresenta-se mesmo como um segmento consolidado em vários países, tanto por via da existência de muitos e diversos jardins, festivais e eventos relacionados, como por via de um enraizado hábito cultural de visita aos mesmos. Os dados dos visitantes revelados para os EUA, Reino Unido, França, Áustria entre outros assim o confirmam.

No contexto português, à parte de um desconhecimento geral relativamente à temática, outros há, nomeadamente proprietários/gestores de jardins, operadores turísticos e consumidores, que há muito o descobriram, desenhando-se como um dos turismos de nicho de grande relevância no seio da atividade turística global nacional, atestada principalmente através da frequência de visitantes registada nos jardins da Madeira e em alguns casos localizados no Continente, cuja informação é conhecida.

Alguns problemas na sua imposição e desenvolvimento de forma consolidada persistem, mormente a falta de investigação e de informação sobre o tema e área de 
negócio, a subestimação do seu potencial, a degradação e abandono de muitos jardins, muito por falta de um inventário mais completo. Porém, existe todo um conjunto de jardins históricos que congregam características únicas da tradição e cultura portuguesas, muitas delas restritas ao território português, e um público específico que os "consomem". Estas oportunidades têm sido aproveitadas por operadores turísticos nacionais mas sobretudo internacionais que "vendem" o produto turismo de jardins em Portugal, que goza ainda de uma grande margem de progressão, e tem potencial para se transformar em algo mais do que um nicho turístico.

\section{REFERÊNCIAS}

AUSTRALIAN BUREAU OF STATISTICS (ABS). Disponível em: <www.abs.gov.au>. Acesso em: 30/06/2011.

ANDRADE, I. Construção e desconstrução do conceito de jardim histórico. Risco, v. 8 (2), p. 138-144, 2008.

AÑóN, C. F. Presentación. Jardins et Sites Historiques. ICOMOS-IFLA International Committee on Historic Gardens and Sites. Madrid: Fundation Cultural Banesto, p. 2526, 1993.

APJSH - ASSOCIAÇÃO PORTUGUESA DOS JARDINS E SÍTIOS HISTÓRICOS. Disponível em: <http://www.jardinshistoricos.pt/estatutos.php>. Acesso em: 02/01/2012.

ARAMA-CARREL, S. Les jardins, un marché en floraison. Faena Études Marketing, 2006.

ARAÚJO, I. A arte paisagista e dos jardins em Portugal. Lisboa: Direção Geral dos Serviços de Urbanização, 1962.

ASSUNÇÃO, P. Jardins, A Arquitectura e Turismo. In: FRANCO, J.; GOMES, A. (Coord.) Jardins do Mundo - discursos e práticas. Funchal: Gradiva, 2008. p. 309322.

BENFIELD, R. Garden Tourism. London: Butterworth Heinemann-Elsevier, 2013.

BHATTI, M.; CHURCH, A. I never promised you a rose garden: gender, leisure and home-making. Leisure Studies, v. 19 (3), p. 183-197, 2000. 
BLANDIGNERES, M.; RACINE, M. Le tourisme de jardins en France: panorama de l'offre. Paris: Cahiers de l'AFIT, 2002.

CARAPINHA, A. Inventário da Arte Paisagista em Portugal. Provas de Aptidão Pedagógica e Capacidade Científica. Universidade de Évora, Évora, 1985.

CASTEL-BRANCO, C. Jardins e Jardins Históricos. In: CASTEL-BRANCO, C. (Coord.) Jardins Históricos. Poesia atrás dos Muros, Colecção Símbolos e Testemunhos Portugueses. Lisboa: Edições Inapa, 2002. p. 9-23.

CARITA, H.; CARDOSO, H. Tratado da Grandeza dos Jardins em Portugal. Edição de Autores, 1987.

CONNELL, J. The Purest of Human Pleasures: the Characteristics and Motivations of Garden Visitors in Great Britain. Tourism Management, p. 229-247, 2004.

CONNELL, J.; MEYER, D. Modelling the Visitor Experience in gardens of Great Britain. Current Issues in Tourism, v. 7 (3), p.183-216, 2004.

CONNELL, J. Managing Gardens for Visitors in Great Britain: a Story of Continuity and Change. Tourism Management,v. 26 (2), p.185-201, 2005.

DELADERRIÈRE, B. Le tourisme de jardins, quels enjeux?. Revue Parcs\&Jardins, 24/11, p. 10-12, 2004.

DIE GARTEN “Garden Tourism” as an international trend: background and facts. Niederosterreichs, St. Polten: Die Garten, 2007.

DRTM Estatísticas do Turismo 2006-2010. Madeira: Secretaria Regional do Turismo e Transportes - Direção Regional do Turismo, 2011 a.

DRTM Taxas de ocupação durante os eventos de animação turística efetuadas por sondagem. Madeira: Secretaria Regional do Turismo e Transportes - Direção Regional do Turismo, 2011b.

EEA GRANTS. Disponível em: < http://eeagrants.org/>. Acesso em: 25/02/2012.

EVANS, M. Gardens tourism - is the market really blooming?. Tourism Insights Sharing sector expertise, analysis and intelligence, v. 12 (4), p. 153-159, 2001.

FOX, D. The influence of social and material agents on garden visiting in England. Progressing Tourism Research, 30-31 March, University of Exter, 2006.

FOX, D. Understanding garden visitors: the affordances of a leisure environment. PhD Thesis. Poole (UK): Bournemouth University, Department of Philosophy, 2007.

FUNDAÇÃO CASAS DE FRONTEIRA E ALORNA Relatórios Anuais. Lisboa: Palácio Marquês da Fronteira, 2012. 
FUNDAÇÃO SERRALVES Relatório de 2011. Porto: Fundação de Serralves, 2012.

ICOMOS. Historic Gardens - The Florence Charter 1981. Paris: International Council on Monuments and Sites, 1982.

IGESPAR - INSTITUTO DE GESTÃO DO PATRIMÓNIO ARQUITETÓNICO E ARQUEOLÓGICO. Disponível em: <http://www.igespar.pt>. Acesso em: 02/11/2012.

JOHNSON, B. The changing face of the Botanic Garden. In: MCCORQUODALE, Th. (Eds) Botanic gardens - a living history. Black Dog Publishing, 2007. p. 64-80.

LUMMEN, A. M. La memoria de la História. Simposio Los Jardines Históricos. Aproximation Multidisciplinaria, 2001.

MCC - MINISTERE DE LA CULTURE ET DE LA COMMUNICATION Décret $n^{\circ}$ 2003-447 du 19 mai 2003 portant création du Conseil national des parcs et jardins, 2003. Disponível em : <www.rendezvousauxjardins.culture.fr>. Acesso em: $21 / 03 / 2012$.

MCC - MINISTERE DE LA CULTURE ET DE LA COMMUNICATION. Disponível em: <www.rendezvousauxjardins.culture.fr>. Acesso em: 21/03/2012.

MINTER, S. Sustainable tourism and botanic gardens - a Win-Win situation. Roots. v. 1 (1), p. 12-15, 2004.

MÜLLER, D. Phänomen "Gartentourismus" ein theoretischer Bezugsrahmen. In: Kultur als touristischer Standortfaktor. Potenziale - Nutzung - Management. Paderborn, 2011. p. 101-113.

NETTO, A. P.; GAETA, C. Turismo de Experiência. São Paulo: Editora Senac, 2011.

NOVELLI, M. Niche Tourism. Contemporary issues, trends and cases. Oxford: Butterworth-Heinemann, 2005.

ONTARIO GARDEN TOURISM COALITION (OGTC) Ontario Garden Tourism Strategy. Ontario: Brain Trust Marketing \& Communications, 2011.

PECHÈRE, R. La restauration des jardins historiques et la philosophie du coloque, 1971. In : Jardins et Sites Historiques. ICOMOS-IFLA International Committee on Historic Gardens and Sites. Madrid: Fundation Cultural Banesto, 1993. p. 29-30.

PECHÈRE, R. Memorandum sur la naissance et les origines de l'IFLA et du Comité International des Jardins et des Sites Historiques ICOMOS-IFLA, 1987. In: Jardins et Sites Historiques. ICOMOS-IFLA International Committee on Historic Gardens and Sites. Madrid; Fundation Cultural Banesto, 1993. p. 259-261.

PORTUGAL. MINISTÉRIO DO FOMENTO Lei no 118 de 16 de março de 1914. Diário do Governo I Série - No 39, Lisboa: Imprensa Nacional de Lisboa, 1914. 
PORTUGAL. MINISTÉRIO DAS FINANÇAS Decreto-Lei $n^{\circ}$ 28:468 de 15 de fevereiro 1938. Diário do Governo I Série - $\mathbf{N}^{\mathbf{0}}$ 37, Lisboa: Imprensa Nacional de Lisboa, 1938.

PORTUGAL. ASSEMBLEIA DA REPÚBLICA Lei n ${ }^{\circ}$ 107/2001 de 8 de setembro de 2001. Diário da República - I Série-A, Lisboa: Imprensa Nacional - Casa da Moeda, 2001 .

PORTUGAL. ASSEMBLEIA DA REPÚBLICA Lei n. ${ }^{\circ}$ 53/2012 de 5 de setembro de 2012. Lisboa: Diário da República I Série - N. ${ }^{0}$ 172, Lisboa: Imprensa Nacional Casa da Moeda, 2012a.

PORTUGAL. MINISTÉRIO DA ECONOMIA E DO EMPREGO Plano Estratégico Nacional do Turismo (PENT) - Horizonte 2013 - 2015, Lisboa: Ministério da Economia e do Emprego, 2012b.

QUINTAL, R. A importância dos jardins como nicho turístico na Madeira. In: SIMÕES; J.; FERREIRA, C. (Eds.) Turismos de nicho: motivações, produtos, territórios. Lisboa: Centro de Estudos Geográficos da Universidade de Lisboa, 2009. p. 71-93.

RENAISSANCE TOURS. Disponível em: <http://renaissancetours.com.au/>. Acesso em: $14 / 07 / 2012$.

RÉPUBLIQUE FRANÇAISE. Loi sur les monuments historiques du 31 décembre 1913. Journal Officiel de la République Française, 4 janvier 1914.

RÉPUBLIQUE FRANÇAISE. Loi du 2 mai 1930 relative à la protection des monuments naturels et des sites de caractère artistique, historique, scientifique, légendaire ou pittoresque. Journal Officiel de la République Française, 4 mai 1930.

ROSS TOURS. Disponível em: <www.rosstours.com>. Acesso em: 02/04/2012.

SÁ CARNEIRO, A. R.; SILVA, A. F.; MAFRA, F. The restoration of Burle Marx gardens in Recife and the vision of paradise of the Florence Charter. City \& Time, v. 3 (2): 9, p. 109-119, 2007.

SHARPLEY, R. Flagship attractions and sustainable rural tourism development: the case of the Alnwick Garden, England. Journal of Sustainable Tourism, v. 15 (2), p. 125-143, 2007.

SIMÕES, J.; FERREIRA, C. Nota de Abertura. In: SIMÕES, J. e FERREIRA, C. (Eds.), Turismos de nicho: motivações, produtos, territórios. Lisboa: Centro de Estudos Geográficos da Universidade de Lisboa, 2009. p. 7-8.

SIMKOVIC, P. Restoration of historical parks with regard to their dendrological value, 1977. In: Jardins et Sites Historiques. ICOMOS-IFLA International Committee on Historic Gardens and Sites. Madrid: Fundation Cultural Banesto, 1993. p. 139-142. 
SIPA E IHRU - SISTEMA DE INFORMAÇÃO PARA O PATRIMÓNIO ARQUITECTÓNICO E INSTITUTO DA HABITAÇÃO E REABILITAÇÃO URBANA. Disponível em: <http://www.monumentos.pt>. Acesso em: 02/11/ 2012.

SOARES, A. L.; CHAMBEL, T.; ANDRADE, I. A Associação Portuguesa de Jardins e Sítios Históricos e o Programa EEA Grants. In: CASTEL-BRANCO, C. (Coord.) A água nos jardins portugueses. Lisboa: Edição SCRIBE - Produções Culturais, 2010. p. $142-148$.

TAVARES, A. C. Relatório de Atividades do Jardim Botânico da Universidade de Coimbra 2011. Coimbra: Departamento de Ciências da Vida - FCTUC, 2012.

THOMAS, R. P.; PORTEOUS, G.; SIMMONS, D.G. Garden Tourism and its Potential Organization in Canterbury. Canterbury: Department of Parks, Recreation and Tourism, Lincoln University, 1994.

VISIT ENGLAND. Disponível em: <www.visitengland.org>. Acesso em: 10/12/2012.

VISITMADEIRA. Disponível em: <http://www.visitmadeira.pt/>. Acesso em: 16/04/2012.

VITERBO, F. S. A jardinagem em Portugal: apontamentos para a sua história. Coimbra: Imprensa de Coimbra, 1906.

WILSON, M. Climate change and garden tourism. Tourism Insights - Sharing sector expertise, analysis and intelligence, v. 18 (7), 2009.

Recebido em: 28-01-2013.

Aceito para publicação em: 27-02-2013. 